\title{
Fire extinguishing system in large underground garages
}

Ivan Antonov ${ }^{1}$, Rositsa Velichkova ${ }^{1 *}$, Svetlin Antonov ${ }^{1}$, Kamen Grozdanov $^{1}$, Milka Uzunova ${ }^{2}$, Ikram El Abbassi $^{2}$

${ }^{1}$ Hydroaerodynamis and hydraulic machines, Technical university of Sofia 1000, Bulgaria

${ }^{2}$ Graduate School of Engineering, ECAM-EPMI, France

A R T I C LE I N F O

Article history:

Received: 02 March, 2017

Accepted: 17 April, 2017

Online: 28 April, 2017

Keywords:

Water curtains

Numerical investigation

Fire in garages

\begin{abstract}
A B S T R A C T
In the work is considered an acceptable constructive scheme from a practical point of view at fire extinguishing in underground garages. The garage space is divided into quadrants which covering, for example, 2 cars. In case of ignition on one of them, a sprinkler nozzle system is triggered by the effect of the vertical convective jet. A protective curtain preventing the spread of fire to adjacent vehicles is realized. The solution is based on an integrated method which allows the calculation from hydrodynamic point of view on extinguishing time of the fire extinguishing system.
\end{abstract}

\section{Introduction}

Fire safety in garages for cars is essential and requires taking into account such actions to ensure it. The complexity of the problem requires a development of methods for numerical simulation of heat conduction and mass processes which are solved with the modern methods of CFD.

In the present work a simple method (from a technologically point of view) is offered for solution of the complex problem. It is suggested to isolate the parked in the garage cars in pairs by operating a thick curtain of water at arisen burning. The necessary insulation for solid non-combustible barriers are replaced at this way.

\section{Principal of action}

Referring to Fig. 1 cars are placed to ensure the possibility between the pairs to have enough distance for the implementation of water curtains. In case of burning over the car is formed upward convective flow, due to differences of the density of the products of combustion and the environment. This stream is proportional to the lift force:

*Corresponding Author: Rositsa Velichkova, Technical university of Sofia, Bulgaria | Email: rositsavelichkova@abv.bg

$$
d F_{A}=-\left[\int_{f}\left(\rho-\rho_{o k}\right) g d f\right] d x
$$

where $f$ is the area of fire ignition, $d x$ elementary stretch at vertical direction.

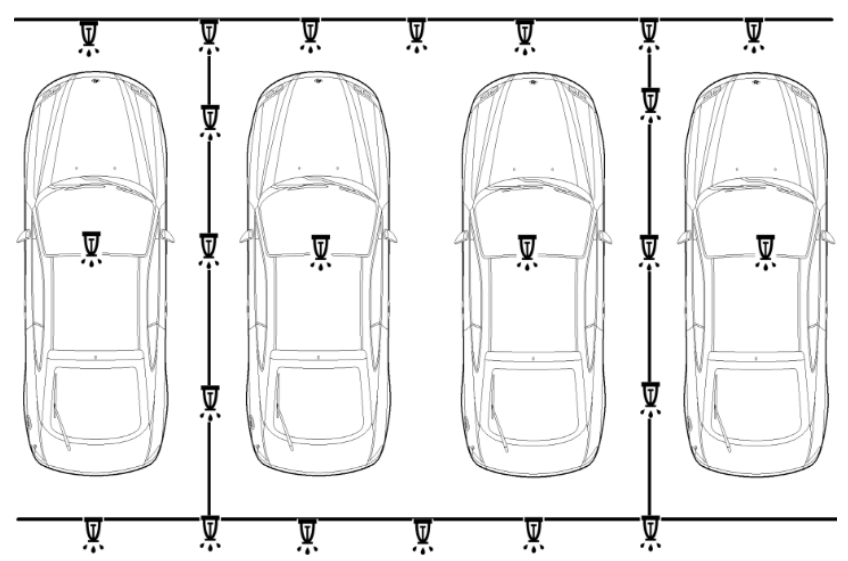

Fig.1 - Distribution of cars in the garages

The power of convective updraft is determined by the number of Archimedes 


$$
A r=\left(\frac{\rho_{o k}}{\rho}-1\right) \frac{g d_{h}}{u_{0}^{2}},
$$

where $d_{h}$ is the hydraulic diameter of the outbreak of fire; $u_{0}$ initial value of the velocity of the upward flow. The velocity is determined according to Drayzdeyl [6]:

$$
u_{0}^{2}=1,9 Q^{1 / 5},
$$

where $Q, k W$ is the power of the fire.

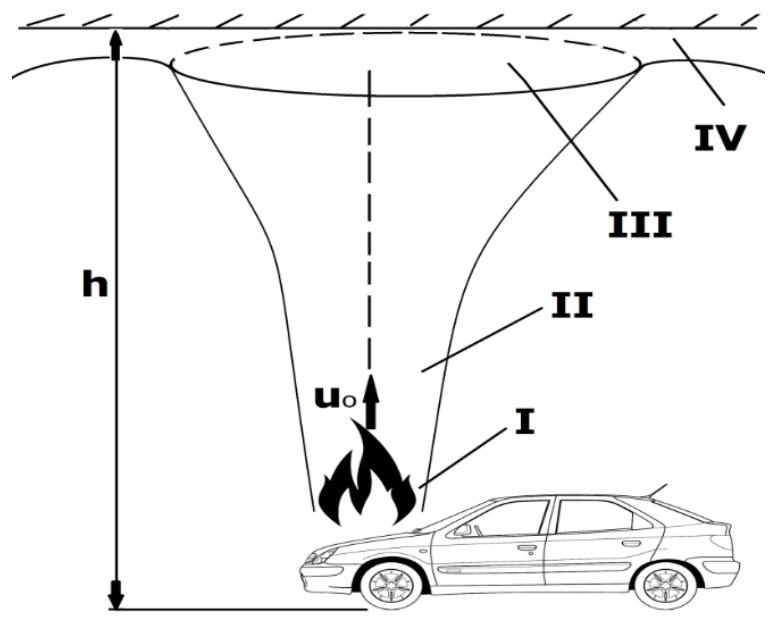

Fig.2 - Distribution of the fire

The formed convective flow is shown in Fig. 2. The conditional arisen stream can be divided into the following areas:

In zone I is formed a convective flow (Fig. 3). In the zone of fire enters from all directions ambient air which is heated and reverses direction in a vertical direction. The second zone is a free convective flow, which continues until it reach the ceiling of the room where the flow changes its character (zone III). In this area the jet is transformed into radial semi-confined stream and spreads along the ceiling of the garage (zone IV).

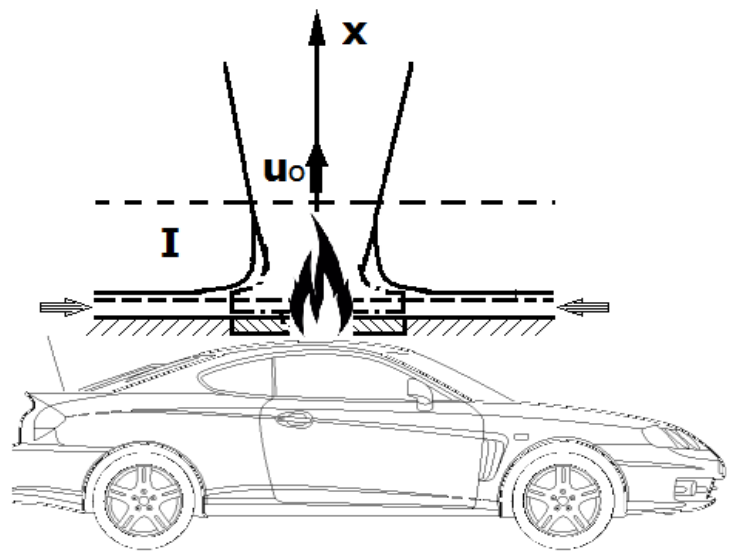

Fig.3 - Sketch of the convective flow

The system includes fire sprinklers- fast response and standard response sprinklers. Reaching the ceiling of the garage under the influence of its temperature convective flow turns on the sprinkler for rapid response and the burning car is flushed with water spray. This is how the process of fire fighting starts in the initial stages Further, spreading out as a radial semi-confined jet reaches the "standard response sprinklers which turns on the water curtain.

This stage is defined as isolating the burning cars from the surrounding area and no affected other pairs.

\section{Mathematical model of convective non-isothermal jet}

For the purpose of solving the task is used an integral method according to [1] [4]. The used equations are as:

-for amount of movement

$$
\frac{d}{d x} \int_{0}^{b} \rho u^{2}\left(\pi y^{j}\right) d y=-g \int_{0}^{b}\left(\rho-\rho_{\text {oк }}\right)(\pi y)^{j} d y
$$

-to preserve enthalpy flow

$$
\frac{d}{d x} \int_{0}^{b} \rho \Delta h u y^{j} d y=0
$$

-for export vertical upward mass flow

$$
\frac{d}{d x} \int_{0}^{b} u\left(\rho-\rho_{o k}\right)(\pi y)^{j} d y=0
$$

A simple decision can be made as (5) of enthalpy is replaced by a linear dependence on the widening of the jet

$$
b=c x
$$

In (4) on the right side is written the Archimedes buoyancy. The included symbols are as follows: $u$ - jet velocity; $y$ - transverse coordinate, $\rho$ - current density, $\rho_{o \kappa}$ - density of the environment, $\Delta h$ - enthalpy of the stream. The exponent $\mathrm{j}$ marks: at $\mathrm{j}=0$-flat stream; $\mathrm{j}=1$ - axis jet. The coordinate $\mathrm{x}$ is directed vertically upwards.

There is a correlation between density and temperature:

$$
\rho=\frac{p}{R T},
$$

where $p$ - pressure of the environment, $R$ - gas constant, $T$ absolute temperature. Similarity to transverse distribution of the velocity and the density (temperature) are initiated [4] [13], where solving (4) and (6) leads to the parameters of the upward convective stream:

- the velocity of the upward stream

$$
u_{m}=B_{u}^{\prime \prime} D_{0}^{1 / 3} \Delta T_{n v}^{4 / 9} x^{-1 / 3}
$$

- the temperature difference

$$
\Delta T_{m}=T_{m}-T_{e n v}=B_{\Delta T}^{\prime \prime} D_{0}^{1 / 3} \Delta T^{8 / 9} x^{-5 / 3},
$$


R. Velichkova et al. / Advances in Science, Technology and Engineering Systems Journal Vol. 2, No. 3, 221-226 (2017)

where $D_{0}$ - initial diameter of the heat source of fire (the burning car); $\Delta T_{1}=T_{f l}-T_{e n v} ; \bar{x}=\frac{x}{D_{0}}$; the constants $B_{u}^{\prime \prime}$ and $B_{\Delta T}^{\prime \prime}$ have values $B_{u}^{\prime \prime}=0,222\left[m^{3} K^{9 / 4}\right], B_{\Delta T}^{\prime \prime}=0,71\left[m^{1 / 3} K^{9 / 8}\right]$.

These values correspond to the case at $\bar{x}=\frac{x}{D_{0}} \geq 3 \div 3,5$. When adopted fire size created from a burning car $D_{0}=0,5 \mathrm{~m}$ and height $H=3 \div 4,5 m, \bar{x}$ of the garage will be always greater than the above values.

At the relatively short distance to the ceiling, the high power of fire (the accepted conditions are $Q=1500 \mathrm{~W}$ and $T=600 \mathrm{~K}$ ), the velocity and the temperature and the rising convective stream doesn't change significantly.

The initial velocity calculated by (3) is $u_{0}=8,2 \mathrm{~m} / \mathrm{s}$ and the time when the convective stream will reach the ceiling at different heights of the garage is given in Table 1.

Table 1

\begin{tabular}{|c|c|c|c|c|}
\hline $\mathrm{h}, \mathrm{m}$ & 3 & 3,5 & 4 & 4,5 \\
\hline$\Delta t$ & 0,36 & 0,43 & 0,49 & 0,55 \\
\hline
\end{tabular}

This means that less than $1 s$ sprinklers over the burning car will be activated and extinguishing stream will flow over the burning car.

The expansion (increasing of thickness) of the jet in height can be determined by the expression:

$$
\frac{d b}{d x}=0,22 \frac{\rho_{0}+\rho_{\text {ок }}}{2 \rho_{\text {ок }}}
$$

respectively

$$
b=\left[0,22 \frac{\rho_{0}+\rho_{o \kappa}}{2 \rho_{o \kappa}}\right] \quad .
$$

The density of the jet in the opening section is defined by (8): at $R=287 \mathrm{~J} / \mathrm{kgK}, T_{0}=600 \mathrm{~K}, p=10^{5} \mathrm{~Pa}$ in which for $\rho_{0}$ is recived $\rho=0,58 \mathrm{~kg} / \mathrm{m}^{3}$. The density of the environment is $\rho_{e n v}=11,2 \mathrm{~kg} / \mathrm{m}^{3}$ at the same pressure and temperature $T_{e n v}=293 \mathrm{~K}$. At this density the widening of the jet in the present case is:

$$
b=0,163 x
$$

For the different height in the garage the parameter $b$ is given in Table 2.

Table 2

\begin{tabular}{|c|c|c|c|c|}
\hline $\mathrm{h}, \mathrm{m}$ & 3 & 3,5 & 4 & 4,5 \\
\hline $\mathrm{b}_{1}, \mathrm{~m}$ & 0,501 & 0,507 & 0,652 & 0,73 \\
\hline $\mathrm{b}_{\text {изт }}, \mathrm{m}$ & 0,651 & 0,77 & 7,74 & 1,98 \\
\hline
\end{tabular}

The last row in Table 2 is given the extension of the isothermal jet $\left(T_{0} \approx T_{e n v}\right)$. Obviously a slight extension of non-isothermal convective flow comparing with the isothermal.

Reaching the ceiling vertical convective stream is transformed into radial jet (Fig. 4).

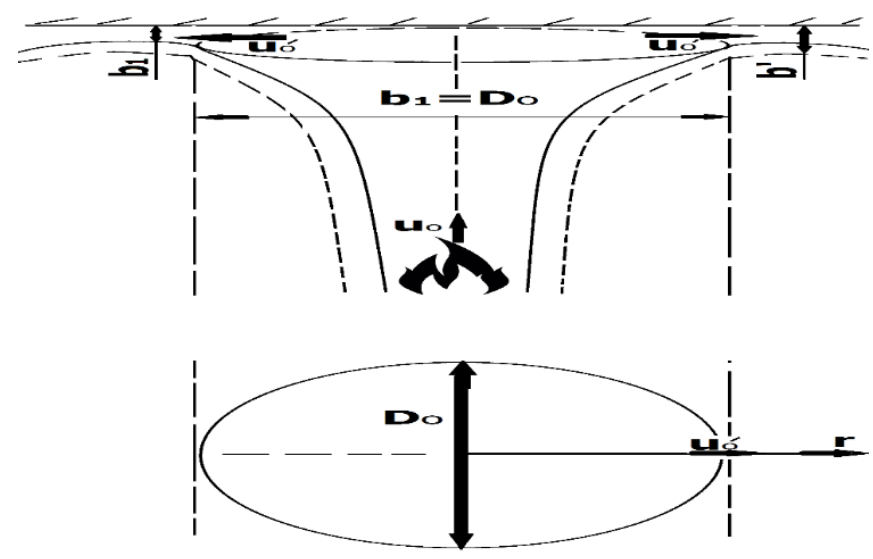

Fig. 4 - Sketch of radial jet

Due to the weak widening of the jet and the short distance to the ceiling the mass flow is not increased significantly because the temperature, density and relatively low mileage ceiling have not changed. The jet has retained its temperature, density and velocity accordig to Abramovich [1] may be determinated:

$$
u_{\max }=0,88 u_{0},
$$

where for $u_{0}=8,2 \mathrm{~m} / \mathrm{s}$ results as $u_{\max }=7,2 \mathrm{~m} / \mathrm{s}$.

It is assumed that the starting size of the radial jet is equal to the obtained in Table 2- $b_{1}$, i.e. $D_{0}=b_{1}$.

Width of the radial jet $b_{0}$ is determined by the flow rate $\mathrm{Q}$ at the intersection of the reverse flow. This flow rate is amount of initial flow rates $Q_{0}$ and increase its height due to suction of air from the environment. Ejecting fluid is considered proportional to the square of the relative increase in the width of the jet $\left(\frac{b_{1}-b_{0}}{b_{0}}\right)^{2}$ and the distance $\mathrm{x}$ divided by the duration of the process $\Delta t$.

$$
Q_{e j} \approx\left(\frac{b_{1}-b_{0}}{b_{0}}\right)^{2} \frac{x}{\Delta t}, m^{3} / s
$$

In this total flow rate is obtained as the sum of normal and ejecting flow rate:

$$
Q=Q_{0}+Q_{e j}, m^{3} / s
$$

where $Q_{0}=u_{0} \frac{\pi d_{n}^{2}}{4}$, when $d_{n}=0,5 m$ and $u_{0}=8, m / s$ we have:

$$
Q=Q_{0}+Q_{e j}=u_{0} \frac{\pi d_{n}^{2}}{4}+\left(\frac{b_{1}-b_{0}}{b_{0}}\right)^{2} \frac{x}{\Delta t}
$$


The flow rate of the respective heights $x=3 ; 3,5 ; 4 ; 4,5 m$ of the garage is shown in Fig. 5 where is defined by the relationship (12), respectively in case of a leak (13).

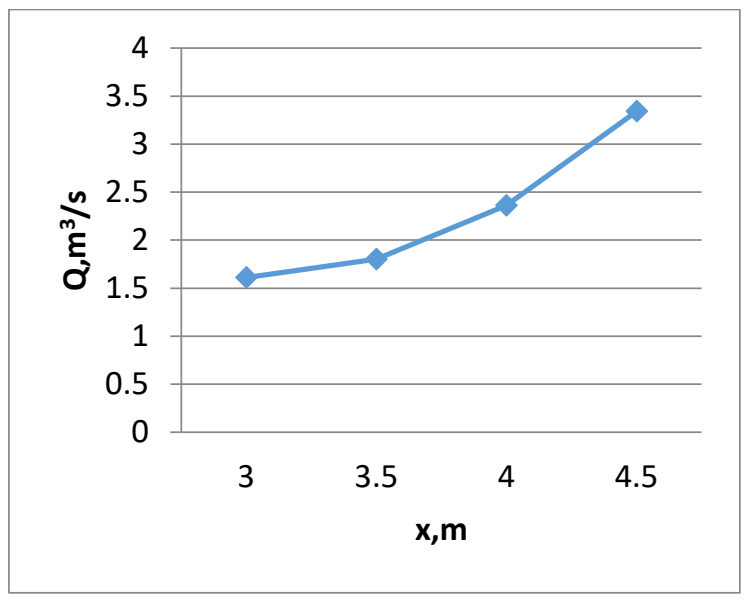

Fig. 5 - Change of the flow rate at different height of the garage

According to Figure 4 is assumed $D_{0}=b_{1}$ that in already known flow rate (16) original width of the radial jet $b_{0}^{\prime}$ is calculated:

$$
b_{0}^{\prime}=\frac{Q}{\pi D_{0}}
$$

The relationship $b_{0}(x)=f(x)$ is given in Figure 6 .

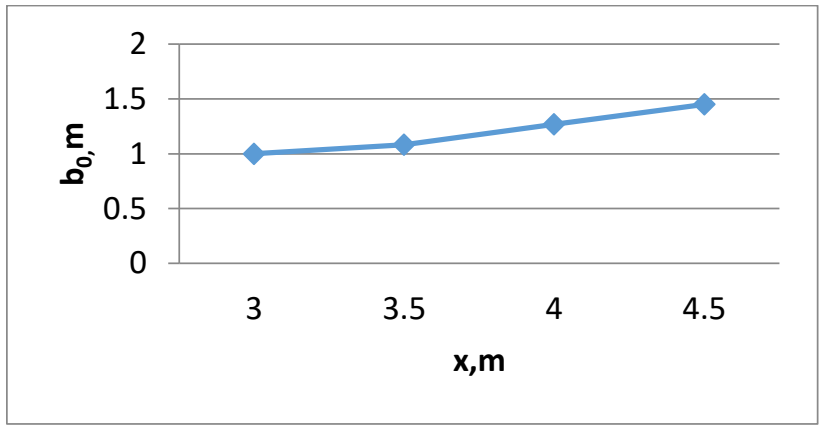

Fig. 6 - Change of the initial weight at different height of the garage

The cross-section of the radial jet, as a function of $r$ is determined by the expression:

$$
S=2 \pi r b^{\prime},
$$

where $r$ is the current radius, $b$ is the width of the jet to the corresponding $r$.

Since the resulting stream is parietal and has parietal boundary layer which thickness is approximately $0,1 b^{\prime}$, than (19) can be recast in the form:

$$
S=2,2 r b
$$

The width $b$ is calculated by (12) and for the case (13) by replacing $\mathrm{x}$ with $\mathrm{r}$ then we have:

$$
b^{\prime}=\left[0,22 \frac{\rho_{0}+\rho_{o k}}{2 \rho_{o k}}\right] r=c^{\prime} r ; c^{\prime}=0,22 \frac{\rho_{o}+\rho_{o k}}{2 \rho_{o k}},
$$

respectively $b^{\prime}=0,163 r$.

Substituted in (19) follows:

$$
S=2,2 \pi c^{\prime} r^{2} \quad .
$$

The average velocity of the ceiling of the room depending on $r$ is obtained by:

$$
u_{m}=\frac{Q}{S} \quad \text {, }
$$

respectively:

$$
u_{m}=\frac{Q}{2,2 \pi c^{\prime} r^{2}}, m / s
$$

Parking average velocity depending on $r$ about the four heights is shown at Fig. 7. Fig. 8 shows the time to reach the appropriate distance.

$$
\Delta t=\frac{r}{u_{m}}, s
$$

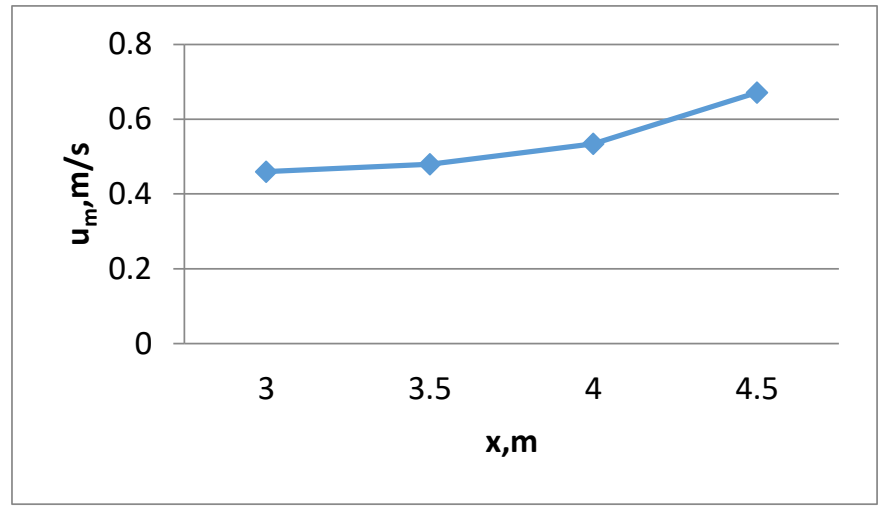

Fig. 7 - Average velocity at different height of garage

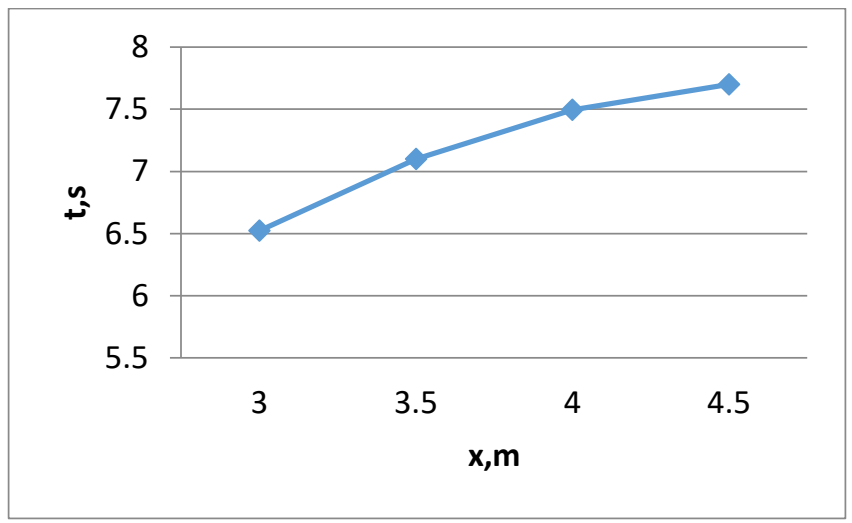

Fig. 8 Time to reach the sprinklers at different height of garage

This means that in the first two seconds all sprinklers at distance of $2 \mathrm{~m}$ away from the burning car will be triggered. For longer distances the remote sprinklers will act at a condition if the temperature of the burning car doesn't decrease too quickly. For maximum calculated time of 7,7 seconds could not be expected too much decrease of the temperature, which leads to the conclusion that the ceiling temperature will be much greater than the starting temperature of "fast" sprinklers so that at $t_{p}=57^{0} \mathrm{C}$ 
or $\mathrm{T}=330 \mathrm{~K}$ will always remain less than the temperature of the wall jet which initial temperature is $600 \mathrm{~K}$.

With the removal from the water curtain it is possible to turn on the other ceiling sprinklers which are in the range.

In the vicinity of the burning car to sprinkler curtain $l \leq 2 m$ will trigger 3 (to 5) fast sprinklers. At a longer distance it will trigger maximum of three quick sprinklers of water curtain plus the main ones over the burning car and eventually these which are lying in the range of $l=4 m$ ceiling sprinklers so that the number of activated sprinklers will increase [5].

To create a smokeless zone under a layer of smoke floating [6] it is designed and installed air exhaust systems for smoke and hot gases. An exhaust ventilation system for smoke and hot gases is a scheme of safety equipment designed to perform a positive role in spin fire. The smoke is drawn in the direction of the non carrier partition EI from of $2 \mathrm{~m} / \mathrm{s}$ to $5 \mathrm{~m} / \mathrm{s}$ velocity. Quoted above standard allowed velocity of $5 \mathrm{~m} / \mathrm{s}$, but it should be taken into consideration that this velocity would affect negatively and lead to the merging of streams of pure air.

From [6] the density of the thermal load in the premises for the storage of combustible materials according to their purpose, is determined the heat capacity of the prevailing materials. Ventilation systems to remove smoke and heat (VSRSH) have to reach its designed performance level within 60 seconds of receiving the command signal. Each VSRSH systems has to ensure receipt of sufficient fresh air that enters the room for the expense of the flue products.

\section{Thermal impact}

Heat transfer by convection and radiation is defined according to [5]. Thermal effects are expressed by the intensity of the heat flow $h_{n b t}, W / m^{2}$ to the surface of the element is determined taking into account the heat transfer by convection and radiation, such as:

$$
h_{n b t}=h_{n b t, c}+h_{n b t, r}, W / m^{2},
$$

where: heat transfer by convection $h_{n b t, c}$ is given by the relationship

$$
h_{n b t, c}=\alpha_{c}\left(\theta_{g}-\theta_{m}\right), W / m^{2}
$$

radiation heat transfer $h_{n b t, r}$ is given by the dependence:

$$
h_{n b t, r}=\Phi \varepsilon_{m} \varepsilon_{f} \sigma\left[\left(\theta_{1} r+273\right)^{2}-\left(\theta_{m}+273\right)^{4}\right], W / m^{2}(28)
$$

Convection component of the intensity of the heat flow is determined by:

$$
h_{n b t, t}=\alpha_{c}\left(\theta_{g}-\theta_{m}\right), W / m^{2}
$$

where: $\alpha_{c}$ is the heat transfer coefficient by convection $\left[\frac{W}{m^{2}} K\right]$ ; $\theta_{g}$ is the gas temperature near the exposed fire element $\left[{ }^{0} \mathrm{C}\right], \theta_{m}$ is the surface temperature of the element $\left[{ }^{0} \mathrm{C}\right]$

The coefficient of heat transfer by convection $\alpha_{c}$ is determined by the nominal curves corresponding to "temperaturetime". On indirectly heated surface elements the intensity of heat flow $h_{n b t}$ is determined by the relationship (16) where $\alpha_{c}=4\left[\frac{W}{m^{2}} K\right]$. The coefficient of heat transfer by convection has value $\alpha_{c}=9\left[\frac{W}{m^{2}} K\right]$, considering that the effects of heat transfer by radiation are included. Radiating components of net heat flux per unit surface area is defined as:

$$
h_{n b t, r}=\Phi \varepsilon_{m} \varepsilon_{f} \sigma\left[\left(\theta_{1} r+273\right)^{2}-\left(\theta_{m}+273\right)^{4}\right], W / m^{2}(17)
$$

where: $\Phi$ factor of configuration, $\varepsilon_{m}$ emitting surface element, $\varepsilon_{f}$ transmission of fire, $\sigma=5,67.10^{8}\left[\frac{W K^{4}}{m^{2}}\right]$ constant of Stefan - Boltzmann, $\theta_{r}$ is the effective temperature of the radiation environment $\left[{ }^{0} \mathrm{C}\right], \theta_{m}$ is the surface temperature of the element $\left[{ }^{0} \mathrm{C}\right]$. Transmission of fire is taking equals $\varepsilon_{f}=1$

\section{Determination of the intensity of water curtain}

Because of the difficulties associated with the construction of fire walls, experiments are conducted so that these areas to be reduced to such proportions that the primarily split up do not disturb of the process. In many cases, such as in buildings of first degree of fire resistance, as already noted, firewalls did not provide the detriment of fire safety. In connection with this arises a need of using such fire barriers that could effectively limit the spread of fire and at the same time would give some freedom for internal layout of buildings with different functions which is the case of the water curtain.

When calculating the water curtains, the assumption of the simultaneous satisfacties the following conditions:

Structural parts of the building to withstand the effects of fire on one side and the passage of flames or hot gases to be prevented by the transfer of heat to the unexposed side. The ability of the structural parts of the building to withstand the effects of fire on one side and prevent the transfer of heat from the exposed to the unexposed side. The transfer is limited so that it does not ignite neither unexposed surface, nor any other material in the immediate vicinity. The structural element is designed to serve as a barrier against the heat and to ensure the protection of people who are close to it.

The effectiveness of water curtains is assessed according to the amount absorbed heat.

It is known that the dependence of the growth temperature of the source of radiation of maximum energy is moving to the side of the shorter waves. This follows from the law of Vin:

$$
\lambda_{\max , T} T=0,29=\text { const }
$$

where: $\lambda$ is the wavelength in $\mathrm{m}, \mathrm{T}$ - temperature at the surface of water curtain, ${ }^{0} \mathrm{~K}$.

Good enough inter-phase and heat absorbing surface has a water drops at size $200.10^{-6}$. It is considered that in the best case, sprinklers spray water less then $1000 \mu \mathrm{m}$. 


\section{Required flow rate for air curtain}

The current aim is decide on the following characteristics - density of the radiation heat flux is $1500 \mathrm{~W} / \mathrm{m}^{2}$; density of the irradiation protected material is $900 \mathrm{~W} / \mathrm{m}^{2}$; height of the hole -4 $\mathrm{m}$; length of the hole $-6 \mathrm{~m}$; pressure of water in sprinkler - 0.6 $\mathrm{MPa}(6 \mathrm{~atm})$ and the radius of the water drops $-0,0006 \mathrm{~m}(600 \mu \mathrm{m}$ ).

Opacity density of the curtain:

$$
\delta=\frac{2,303 \log q_{\text {изл }}}{q_{\kappa p}}=0,51
$$

Thickness of the curtain:

$$
R=\frac{\delta}{c}=\frac{0,51}{2,8}=0,182 m
$$

Flow rate of the water curtain for $1 \mathrm{~m}^{2}$ of lateral surface is defined by:

$$
Q=0,666 \mu \rho \frac{r R}{H} \sqrt{2 g h}=0,467 \frac{l}{s} m^{2}
$$

For the whole surface of the water curtain:

$$
Q^{H}=11,2 l / s
$$

Water curtains are constructed so that the entire hole is irrigated with finely dispersed water. For this purpose sprinklers are placed over the hole and next to it. When they are placed at the top of the hole it is possible to remain unprotected areas through which is possible a penetration of hot gases to occur.

Sprinkler heads which are used to spray jets are spaced $0.5 \mathrm{~m}$ in protecting small holes and $1.25-1.5 \mathrm{~m}$ in protecting large holes. For sprinkler heads water curtains which are situated at a distance greater than $3 \mathrm{~m}$, it is required head pressure of the water 4-6 $\mathrm{mH}_{2} \mathrm{O}$.

\section{Conclusion}

It is made an approximate fast and easy to implement analysis and calculation of water curtain, which replacing the fire walls with water curtains.

It is advisable that nozzles for spraying the water to be directed vertically upward to cover the entire space of the garage ceiling to the floor, thus help to keep heat away from the curtain.

These minimum values of pressure in their heads provided sufficiently stable curtain of water flows under the pressure of combustion products.

Water extinguishing systems can completely extinguish a fire or to locate it only on condition that they provide the necessary delivery rate extinguishing substances over the area of the fire.

The proposed firefighting system has some limitations in technical field: secure enough water for the sprinkler system; the entering into the garage cars must be with no Liquefied Petroleum Gas fuel (this condition is not easy to control); the fire extinguishing and prevention of the thermal radiation diffusion system ensure state of safety in the first $10-15$ minutes from the occurrence beginning- after that time the firefighting department must act in this zone.

\section{Additional contributions}

It is developed a new fire extinguishing system for configuration and the fire spread to neighboring cars in the garage.

On the basis of an integral method it is made a mathematical model for calculating the extinguishing system and it is given also the respective fire extinguishing times.

It is developed a system for fire extinguished in one of the largest underground garages in Sofia using this conseptual design. The fire extinguishing system described in this article is implemented in fire extinguishing practice after its adoption by specialized scientific councils by authorized institutions (institutions).

\section{References}

[1] Abramovich, Theory turbulentnyiy Strings, Moscow 1984

[2] Annica Nordmark, Fire and life safety for underground facilities: present status of fire and life safety principles related to underground facilities: ITA working group 4, "subsurface planning", Tunnelling and Underground Space Technology, Volume 13, Issue 3, July-September 1998,pp 217-269

[3] Annex № 9 of art. 122, para. 3 NSTPNOBP

[4] Antonov IC, Applied Fluid Mechanics, Sofia 2010

[5] A.W. Marshall, M. di Marzo, Modeling Aspects of Sprinkler Spray Dynamics in Fires, Process Safety and Environmental Protection,vol 82, Issue 2, March 2004, pp 97-104

[6] Drysdale D. An introduction to fire dynamics, John Wiley sons, 2011

[7] Eurocode 1 - Impact on stoitelni structures, Part 1-2

[8] EN-12845, Installation and Maintenance of fixed sprinkler systems in buildings and industrial plants

[9] Ivan Antonov, Rositsa Velichkova, Kamen Grozdanov, Milka Uzunova, The possibility of replacing solid walls with water curtain applicable to a large underground garage, EFEA'2016, Belgrade, Serbia, http://ieexplore.ieee.org/document/774880/,DOI: 10.1109/EFEA.2016.77 48805, Electronic ISBN: 978-1-5090-0749-3

[10] G.D. Lougheed, J.K. Richardson, Sprinklers in Combustible Concealed Spaces, Journal of Fire Protection Engineering, May 1989; vol. 1.2 pp.4961.

[11] Jian-yong Liu, De-ming Zhu, Zhe Zhao, Dong Liang ,Experimental Study on Ultra-Fine Water Mist Extinguishing Heptane Cup Fire in Confined Space, Procedia Engineering,vol 52, 2013,pp 225-229

[12] Noureddine Benichou, Ahmed H. Kashef, Irene Reid, George. V. Hadjisophocleous, David A. Torvi, Gaetan Morinville, FIERAsystem: A Fire Risk Assessment Tool to Evaluate Fire Safety inIndustrial Buildings and Large Spaces,Journal of Fire Protection Engineering, August 2005; vol.15,pp.145-172.

[13] Rositsa Velichkova, Ivan Antonov, Kamen Nikolov, Kamen Grozdanov, Milka Uzunova, Modeling of the occurrence of fire in closed cars garages, EFEA'2016,http://ieeexplore.ieee.org/document/7748807/,DOI: 10.1109/E FEA.2016.7748807, Electronic ISBN: 978-1-5090-0749-3

[14] V. Stoyanov, A. Terziev , M. Uzunova, "Numerical study of distribution of smoke and hazards in underground parking areas considering the operation of ventilation,"Environmental Friendly Energies and Applications (EFEA), 2014 3rd International Symposium on, St. Ouen, 2014, pp. 1-6

[15] Vijay Kumar Cheeda, Amit Kumar, K. Ramamurthi, Influence of height of confined space on explosion and fire safety Fire Safety Journal,vol 76,August 2015,pp 31-38

[16] Xin Ye, Jian Ma, Yi-xin Shen, Long-yuan Lin, Suppression Effect of Sprinkler System on Fire Spread in Large Commercial Buildings , Procedia Engineering,vol 135,2016,pp 454-461

[17] Xiangyang Zhou , Characterization of interactions between hot air plumes and water sprays for sprinkler protection, Proceedings of the Combustion Institute, vol 35, Issue 3,2015, Pages 2723-2729 